\title{
Who's Afraid of Organization? \\ Concepts, Process and Identity Thinking
}

Johnsen, Christian Garmann

Document Version

Accepted author manuscript

Published in:

Philosophy of Management

DOI:

10.1007/s40926-017-0079-5

Publication date:

2018

License

Unspecified

Citation for published version (APA):

Johnsen, C. G. (2018). Who's Afraid of Organization? Concepts, Process and Identity Thinking. Philosophy of Management, 17(3), 303-319. https://doi.org/10.1007/s40926-017-0079-5

Link to publication in CBS Research Portal

\section{General rights}

Copyright and moral rights for the publications made accessible in the public portal are retained by the authors and/or other copyright owners and it is a condition of accessing publications that users recognise and abide by the legal requirements associated with these rights.

Take down policy

If you believe that this document breaches copyright please contact us (research.lib@cbs.dk) providing details, and we will remove access to the work immediately and investigate your claim. 


\section{Who's Afraid of Organization?: Concepts, Process and Identity Thinking Christian Garmann Johnsen}

Journal article (Accepted version)

CITE: Who's Afraid of Organization? Concepts, Process and Identity Thinking. / Johnsen, Christian Garmann. In:

Philosophy of Management, Vol. 9, №. 1, 2018, p. 303-319.

This is a post-peer-review, pre-copyedit version of an article published in Philosophy of Management. The final authenticated version is available online at:

https://doi.org/10.1007/s40926-017-0079-5

Uploaded to CBS Research Portal: January 2019 


\title{
Who's afraid of organization? Concepts, process and negative dialectics
}

\author{
Abstract \\ This paper argues that we should not abandon the noun 'organization' in favour of the verb 'organizing' in \\ order to capture processes of change, flow and movement, but instead explore how such processes reveal \\ themselves when the concept of organization diverges from the objects it is supposed to encapsulate. Here I \\ make use of Adorno's negative dialectics in order to show how the experience of organizational phenomena \\ remains trapped within a contradiction: we need to use concepts to describe objects even though concepts can \\ never fully exhaust the objects they describe. However, I maintain that it is precisely this discrepancy between \\ concepts and objects that provides us the opportunity to experience the elusive state of organizations and their \\ processual nature. Consequently, this paper presents a 'negative dialectics of organization', showing how \\ organizational phenomena are always more complex, temporal and dynamic than what the concept of \\ organization permits us to grasp.
}

\section{Keywords}

Process theory, verb-noun, identity thinking, concepts, negative dialectics, organization 


\section{Introduction}

Since Weick (1979: 44; 1995: 188) called for organizational scholars to study the verb 'organizing' instead of the noun 'organization', process-based approaches have gained momentum in organization studies (Anderson, 2006; Bakken and Hernes, 2006; Hernes and Weik, 2007). In turn, recent years have witnessed a growing interest in capturing how processes of organizing, movement and change take place by foregrounding concepts such as 'becoming' (Chia, 1999; Clegg, Kornberger and Rhodes, 2005), 'relationality' (Cooper, 2005), 'patterns' (Zundel, Holt and Cornelissen, 2013) and 'multiplicity' (Linstead and Thanem, 2007). But along with this trend, some scholars have complained that organization studies has lost sight of organizations as distinct social entities. Since a processual approach puts emphasis on 'organizing', the 'organization' as object, according to these critics, has been cast into the shadows of organization studies. For instance, King, Felin and Whetten maintain that as a consequence of 'stamping in verbs, the organization as a distinct sort of entity has become invisible' (2010: 290). In their view, the move towards a processual approach to organizing has effectually deprived organization studies of its core object, namely the organization itself. Echoing Foucault, Lopdrup-Hjorth goes so far as to suggest that organization studies currently suffers from 'organization-phobia' (2015: 441) — that is, a fear of engaging with the organization as such.

In this paper, I address the problem of conceptualizing the noun 'organization' from a processual perspective. To do so, I will show how we can engage with the concept of the organization by making use of Adorno's negative dialectics. The dominant approach has been to analyze organization as a specific empirical 'object' (Lopdrup-Hjorth, 2015) or circumscribed 'social entity' (King et al., 2010) with distinct properties that can be theoretically identified. However, I will argue that organization is first and foremost a concept designed to categorize, describe and represent certain objects (Willmott, 2014). This shift of perspective has important implications, because it allows us to frame the problem in the following way: The attempt to conceptualize organization has conventionally proceeded on the basis of constructing a taxonomic category—or what Hirsch and Levin (1999) call an umbrella construct-intended to classify a variety of different organizational forms and types. Following Adorno, such an approach involves 'identity 
thinking' (Mumby, 2005; Neimark and Tinker, 1987; Parker, 2003), since theorizing consists of constructing a concept of organization that encapsulates the manifestation of different organizational types and forms in practice. Drawing on Adorno's negative dialectics, I will show why identity thinking will always be problematic because of the inevitable discrepancy between concepts and the objects they attempt to describe. Hence, concepts are never able to grasp objects within taxonomic categories without simultaneously betraying their notoriously complex, temporal, indeterminate and changing nature.

Here I will argue that we should not attempt to bridge the gap between the concept and the object by introducing new terminology. Instead, we should highlight the processual nature of organizational phenomena that is invariably revealed when we recognize the contradiction between the concept of organization we utilize and the organizational realities we encounter. Confronted by this contradiction, we can see how organizational phenomena are temporal, multilayered and imputed with change. In order to develop this argument, I will discuss the effort to comprehensively capture all organizational forms and types under a single taxonomic category (King et al., 2010), and the weaknesses of such an approach. However, I do not advocate totally abandoning taxonomic categories by subscribing to a processual view that favours dynamic verbs (Weick, 1995). As an alternative approach, I maintain that we should continue to engage with the concept of organization, but that we remain aware of the contradictions that occur in the attempt to subsume organizational phenomena under an ambitious taxonomic category. My alternative formulation is what I call a 'negative dialectics of organization' which consists of showing how the objects encountered in organizational realities are always richer, more complex, and more dynamic than what the concept of organization permits us to grasp. The challenge of thinking about organization is to think about what it is that escapes the very concept of organization we are proposing. To this end, I will argue that negative dialectics can elucidate what identity thinking leaves in the shadows, namely the elusive and indeterminate nature of organizational phenomena.

The paper is structured into four sections. The first section discusses the attempt by organization researchers to replace the noun 'organization' with the verb 'organizing' in order to capture processes of change, flow and movement. Here I draw on critiques of Weick's work and suggest 
that Adorno's negative dialectics can allow us to reformulate the problem of conceptualizing organization. The second section introduces Adorno's idea of negative dialectics and its applicability to the concept of organization. Here I show how negative dialectics can add to prior critiques of organizational concepts in their taxonomic variants. The third part of the paper shows how negative dialectics can be used to explore the contradiction between the concept of organization and those objects it subsumes. For this purpose, I use an example from my own experience of studying organization. The final part shows how the negative dialectics of organization can expose how the concept of organization breaks down in its attempt to categorize, represent and subsume organizational realities. The paper concludes by reiterating that objects always bear testimony of the fact that things could be otherwise, a condition that is essential for understanding organizational phenomena as processual, multi-layered and elusive.

\section{From verbs to nouns and back again}

In recent years, organizational studies has revolved around how to conceptualize the processes of change, flow and movement (Helin, Hernes, Hjorth and Holt, 2014; Chia, 1999; Shotter, 2006; Nayak, 2008; Clegg et al., 2005; Tsoukas and Chia, 2002; Zundel et al., 2013). The primary issue is whether organizations should be conceived of as 'things' or 'processes' (Tsoukas, 2005). The former perspective stresses that organizations are primarily circumscribed social entities that may evolve over time (King et al., 2010). This view subscribes to a 'weak' process ontology, since movement, flow and change predominately result from the interaction of relatively stable units (Van de Ven and Poole, 2005). Conversely, what Van de Ven and Poole (2005) call a 'strong' process perspective, in the words of Bakken and Hernes, 'work[s] from an ontological viewpoint of the world as process, where entities, as far as they are seen to exist, are products of processes rather than existing prior to them' (2006: 1600). In a strong process account, movement, flow and change have a prior ontological statue to the formation of stable entities (Van de Ven and Poole 2005). Hence, the composition of stable entities emerges only from preceding processes of flow, change and flux (Tsoukas and Chia, 2002). While a weak process ontology takes its point of departure in the idea that the world is constituted by entities that can interact with each other, a strong process ontology proceeds on the basis that social entities are generated by processes of 
change, flow and movement (Bakken and Hernes, 2006; Tsoukas, 2005; Van de Ven and Poole, 2005).

In order to advance a strong processual view within organization studies, researchers have sought to introduce terminology capable of capturing the dynamic character of organizations (Chia, 1999; Clegg et al., 2005; Hjorth, Holt and Steyaert, 2015; Tsoukas and Chia, 2002; Chia and Holt, 2006). For instance, Weik recommends that a 'new language' be 'invented in order to express processual reality' (2011: 659). To achieve this, Weick's (1979) seminal work on sensemaking has been influential, since it stresses the importance of replacing what he considers static nouns with dynamic verbs, in particular the noun 'organization' with the verb 'organizing' (1979: 44; 1995: 188). Hence, Weick contends that the noun 'organization' inevitably 'conceals the fact that organizing is about flows, change and processes' (1995: 187). By replacing nouns with verbs, Weick believes that we can escape the fixed categories that mask the underlying flow of experience, since 'verbs are closer to the dynamics of a process' (1995: 188). Thus, Weick, Sutcliffe and Obstfeld assert that the "language of sensemaking captures the realities of agency, flow, equivocality, transience, reaccomplishment, unfolding, and emergence' (2005: 410). These processes, they continue, are 'often obscured by the language of variables, nouns, quantities, and structures' (Weick et al., 2005: 410). So while the noun 'organization' tends to cover over processes, Weick et al. emphasize that the verb 'organizing' allows us to conceptualize change, flow and movement.

At first glance, Weick's (1995) solution to the challenge of conceptualizing change, flow and movement would seem attractive, since discarding nouns should ideally allow us to describe the processual nature of organization. However, the problem with this approach is that we cannot simply discard the categories we use. As Helin et al., argue, we 'cannot but help use concepts, categories, words' (2015: 10) that coagulate experience once we engage in the study of organizational life. For this reason, Bakken and Hernes argue that 'working exclusively with verbs has its problems', since 'nounmaking is necessary for human sensemaking', adding that 'we are incapable of thinking purely in terms of process' (2006: 160; see also Hernes, 2014: 103). In order to make sense of the world around us, we need to compose categories, nouns and terms 
that render the phenomena we encounter comprehensible, making it impossible to abandon categories, nouns and terms altogether (Bakken and Hernes, 2006).

Moreover, although we attempt to replace nouns with verbs, there is no guarantee that the verbs we deploy in the study of organizational life will not function as fixed categories themselves, solidifying the objects we encounter into immutable things. For example, the verb 'organizing' might be used to designate organization as a static object. With this note of caution in mind, Hernes and Weik emphasize that 'adding "'-ing”' to a noun, however, much it turns produces a verb in linguistic terms, does not do much to affect the way that we actually conceptualize process' (2007: 253). In other words, swapping nouns with verbs does not automatically alter our conceptions of organizational phenomena. On an ontological level, the world might be animated by processes of change, flow and movement. But on an epistemological level, the question is how to conceptualize such processes (Bakken and Hernes, 2006; Nayak, 2008; Helin et al., 2014). Let us therefore pose the following epistemological question: If categories, nouns and concepts are necessary for making sense of the world around us, then how can we gain access to the processes of change, flow and movement that animate organizations?

Some scholars insist that change, flow and movement are 'beyond representation' (Nayak, 2008: 179), while others call on us to create new concepts that allow us to think processually (Chia, 1999). But here I will show how Adorno's (1983) negative dialectics can provide an alternative approach to exploring the processual nature of organizational phenomena. To do so, I will argue that we should not necessarily abandon the noun 'organization' in favour of the verb 'organizing' in order to capture processes of change, flow and movement. Instead of exclusively adopting verbs, we can look for how such processes reveal themselves in precisely those instances when the concept used to understand organization shows itself unable to encapsulate organizational phenomena. It is in these moments of disjuncture that Adorno's negative dialectics might prove useful. The advantage of Adorno's negative dialectics is that without simply replacing nouns with verbs, it can enable us to understand the processual nature of the world by highlighting the discrepancy between the concepts we utilize and the objects we encounter in organizational realities. In doing so, a negative dialectics approach enables us to see how organizational phenomena are always infinitely richer than the concepts we use to describe, 
represent and categorize them. In what follows, I will therefore explore how change, flow and movement emerge in the gap between the concept of organization and those objects it subsumes.

\section{When objects diverge from their respective concepts}

Adorno's (1983) negative dialectics can be contrasted with what he calls positive dialectics. Adorno associates positive dialectics with the threefold scheme of thesis, antithesis and synthesis. This scheme is often used to present dialectics in organization studies (see Nielsen, 1996: 227). Positive dialectics is employed in order to neutralize a contradiction by arriving at a synthesis. In a positive dialectical approach, the thesis and the antithesis are mutually reinforcing. Hence, positive dialectics assumes that it is possible to 'achieve something positive by means of negation' (Adorno, 1983: xix). In this way, the contradiction between the thesis and the antithesis yields a positive synthesis. But while this threefold scheme has become a fashionable way of representing dialectics, Adorno (1983) suggests a fundamental reversal of this way of thinking. He wishes to 'free dialectics from such affirmative traits' (1983: xix) by making dialectics negative instead of positive. Adorno (2008: 6) rejects the thesis - antithesis - synthesis schema because it designates a static portrayal of dialectics (Jameson, 2007). Despite the fact that dialectics should ultimately enable us to think change, flow and movement (Benson, 1977), the thesis - antithesis - synthesis schema, according to Adorno (1983), arrests the movement of dialectical thinking within a logical straitjacket, since every contradiction must conform to this 'inflexible tripartite scheme' (Jarvis, 1998: 168). For this reason, Adorno maintains that scholars using dialectical frameworks should refrain from forming syntheses that mediate between contradictions.

In addition to this critique, Adorno (1983: 141) also objects to positive dialectics, because it operates on the basis of what he calls 'identity thinking' (Mumby, 2005; Neimark and Tinker, 1987; Parker, 2003). Identity thinking posits a specific relationship between concepts and objects. Here concepts are considered taxonomic categories that serve to classify, describe and represent the particular objects that we encounter. Objects are viewed as concrete things or phenomena

given to experience. Conversely, concepts are understood as the taxonomic categories that we use to classify, describe and represent these objects. In order to illustrate the use of identity thinking, 
we might consider the following example: When we say that 'lions and tigers are predators', we evoke the concept of 'predator' to represent, describe and categorize the two objects 'lions' and 'tigers', respectively. Here the concept of predator serves as a category that collapses and conveys common characteristics of lions and tigers, namely that they prey on other animals. In this way, identity thinking consists of subsuming objects under their respective concepts (Stone, 2014). Put somewhat differently, identity thinking forms a synthesis between the concept and object.

Adorno contends that identity thinking is too simplistic, because it overlooks the multifaceted, indeterminate and fluctuating nature of objects. In opposition to identity thinking, Adorno (1983: 145) asserts that instead of conflating objects with their respective concepts, negative dialectics should disclose the discrepancy between the two. To accomplish this, negative dialectics replaces 'synthesis' with 'nonidentity' in the effort to foreground the contradictions rather than neutralize them (Mumby, 2005). Here 'nonidentity' denotes the 'divergence of concept and thing' (Adorno, 2002a: 6). Hence, Adorno insists that objects are never identical with their conceptual representation, since the complexity of every phenomenon exceeds the capacity of concepts to define or represent them. If we return to our previous example, it is evident that the two objects 'lions' and 'tigers' have many traits, characteristics and features beyond the fact that they prey on other animals. For this reason, objects are always more multi-layered than what concepts allow us to recognize. In Adorno's view, negative dialectics should therefore not assume that objects can be reduced to their conceptual representation. Quite the opposite, negative dialectics should reveal how 'the concept enters into contradiction with the thing to which it refers' (Adorno, 2008: 7).

Ultimately, Adorno believes that negative dialectics should foreground what he calls the "priority of the object' (Javis, 1998: 181). This is basically a materialist position based on the premise that objects have an autonomous existence that cannot be represented conceptually (see also Nayak, 2008: 179). Yet Adorno does not assume that objects are homogeneous, coherent and harmonious unities that remain stable across time and space. Rather, negative dialectics acknowledges the 'contradiction in the object itself' (Adorno, 2008: 9). What Adorno suggests here is that the contradiction between concept and object is inherent in the phenomena we encounter in the 
world. To confront the contradiction in the object therefore consists of highlighting the 'nonidentical in the phenomena' (Adorno, 1983: 145). This nonidentical in the phenomena is precisely the dimension of objects that cannot be accounted for by identity thinking. Negative dialectics explores what lies on the edge or hidden beneath the taxonomic categories we use to describe objects. So the discrepancy between concepts and objects, according to Adorno, prepares the way for experiencing the inexpressible processual nature of objects, precisely those characteristics that are not inscribed within taxonomic categories. It is here that Adorno's dialectics becomes negative, disclosing the nonidentity between concepts and objects by confronting the 'indeterminate possibility in the object' (Bernstein, 2006: 39). Within the discrepancy between the concept and the object, Adorno's approach enables us to see how objects are imbued with change. The world of objects that we attempt to describe using concepts is a world that is temporal, ephemeral and fluid.

\section{Negative dialectics and organization}

In what follows, I will show how Adorno's negative dialectics can be used to address the problem of conceptualizing organization. Here I will demonstrate how the prevalent approach to conceptualizing organization has been based upon identity thinking. However, I will also show that negative dialectics allows us to look beyond such conventions. But before proceeding with this endeavour, it is important to emphasize that there are various competing conceptualizations of organization available, depending upon the theoretical perspective one adopts (Tsoukas and Knudsen, 2005). Within the theory of the firm, for example, organizations are portrayed as a bundle of resources, an aggregation of capabilities, a nexus of contracts or transactions within hierarchies. Such views have been criticized for their unilateral focus on the economic aspects of organizational life and their failure to take account of the cultural, linguistic and social dimensions (Hatch and Cunliffe, 2013). In addition, scholars have complained that an economic view of organization fails to call attention to key ethical and political issues. For instance, Parker views organizations as 'politics made durable' (2007: 223) and insists that a focus on organization cannot be reduced to a managerial perspective that favours economic and functional considerations. 
Leaving aside these disagreements for the moment, a common assumption underlying most attempts to conceptualize organization consists of constructing a representational concept that reveals the manifestation of particular organizational arrangements in practice. This effort consists of developing what Hirsch and Levin call umbrella constructs - that is, 'broad concepts used to encompass and account for a diverse set of phenomena' (1999: 199). Such concepts should extract and display the essential characteristics of the phenomena they comprise (Suddaby, 2010). Along these lines, the concept of organization is often used as an umbrella construct designed to account for various organizational types and forms, including private corporations, family businesses, NGOs, public institutions and state bureaucracies (Cunliffe, 2008). Chia notes that organization studies relies heavily upon 'taxonomic classification in the analysis of organizational reality' (1999: 210; see also Helin et al., 2014; Hernes, 2007; Tsoukas and Chia, 2002). Such concepts are not always theoretically based, insofar as practice itself is inextricably fused with taxonomic categories that are used to classify objects (Adorno, 2002a: 32). In many organizations, numerous concepts - articulated through diagrams, models and charts - are used in order to capture, order and systematize the routines, practices and procedures that are conducted on a daily basis (Weick et al., 2005).

Following Adorno, we can see that the enactment of concepts as 'umbrella constructs' (Hirsch and Levin, 1999) involves identity thinking. Recall that identity thinking consists of subsuming objects under concepts by classifying the phenomena encountered in experience under their respective taxonomic categories. 'To think is to identify' (Adorno, 1983: 5) — that is, to identify objects with concepts. To illustrate how conceptualizing organization involves identity thinking, we may use the following example. Cunliffe explains that most conceptualizations of organization 'centre around the idea that organizations are entities in which individuals coordinate their actions to achieve specific goals' (2008: 5; see also Scott, 1998: 11). For instance, Robbins states: 'An organization is a consciously coordinated social entity, with a relatively identifiable boundary, which functions on a relatively continuous basis to achieve a common goal or a set of goals' (1990: 4; for discussion, see Spoelstra, 2007). This view can be traced back to Barnard who considers formal organization a 'cooperative system' wherein people work 'for at least one definite end' (1968: 65). Although these formulations differ in nuances, the 
basic idea expressed here is that organizations are circumscribed 'social entities' (King et al., 2010) within which individuals coordinate and cooperate in order to attain certain collective ends.

Here the concept of organization is deployed as a heuristic device that classifies all particular organizational types, including 'small family-owned businesses or multinational corporations, for-profit or non-profit, private or public, service or product oriented, government agencies' (Cunliffe, 2008: 4), under the same rubric. The concept of organization thus covers a variety of different organizational forms, ranging from bureaucracy to network shaped constellations — what Mintzberg (1983) calls different 'configurations' of organization. This is achieved by distilling the 'common features' (Scott, 1998: 11) of these instances into a single, overarching concept. In effect, the concept of organization functions to subsume particular objects (different organizational forms and types) under a taxonomic category (the concept of organization). Although small family-owned businesses, multinational corporations and other organizational types vary in size, shape and form, they nevertheless share certain basic characteristics that the concept of organization enables us to recognize. Regardless of whether it is a small family-owned business or multinational corporation, they are organizations to the extent that they enable their members to coordinate their actions to achieve specific goals. Without the unifying concept of organization, these objects would be rendered as unrelated phenomena, lacking of a common denominator. The concept of organization thus permits us to recognize a range of forms as a single entity. In this way, the concept of organization proceeds on the basis of identity thinking.

\section{Organization cannot be reduced to a conceptual representation}

Although taxonomic categories figure prominently in organization studies, scholars inspired by process philosophy have increasingly called into question such concepts (Chia, 1999; Helin et al., 2014; Van de Ven and Poole, 2005; Chia and Holt, 2006; Hernes, 2007; Zundel et al., 2013; Shotter, 2006). Before showing how Adorno's negative dialectics can be used to think beyond concepts, we shall look at how these scholars have problematized the use of taxonomic categories. Inspired by Whitehead, Chia shows that concepts understood as taxonomic categories fall victim to the 'fallacy of misplaced concreteness' (1995: 582) which consists of confusing the abstract with the concrete. As Cooper elaborates, taxonomic categories assume that objects are 
entities that can be ascribed a 'simple location in which clear-cut, definite things occupy clearcut, definite place in time and space' (1998: 108, original italics; see also Chia, 1999; Cooper, 1998; Hernes, 2007; Nayak, 2008; Spoelstra, 2007). Such a view pays no attention to the myriad of intricate relations constituting objects. Hence, Cooper argues that taxonomic categories fail to account for the underlying 'relationality' (2005) of the world. As Cooper remarks, 'categories and things may make it easier for us to grasp reality, but they also hide its underlying complexities' (2005: 1689). Contrary to the static view on objects assumed by representational concepts, Hernes maintains that everything 'is in the process of becoming, perpetually' (2014: 20).

Organizational scholars have also explored the performative effects of adopting concepts. As the above example indicated, the concept of organization itself is a way of organizing the world by classifying particular objects under a taxonomic category. Thus, Tsoukas and Chia remark that 'organizing implies generalizing; it is the process of subsuming particulars under generic categories' (2002: 573; see also Weick et al., 2005: 417). In other words, the concept of organization is an active process of providing order to the intrinsic flux of experience by 'selecting certain features and excluding others' (Cooper, 1986: 301). For this reason, the concept of organization is not simply a neutral depiction of a given state of affairs. Instead, the concept of organization produces certain effects, since it organizes experience in a certain way (Hernes, 2007; Cooper, 1986; Tsoukas and Chia, 2002; Clegg et al., 2005). Taking issue with King et al.'s (2010) suggestion that we should recover 'organization' as a 'unique social entity in society', Willmott argues that such a view fails to acknowledge "that "organization" is a concept that retroactively constitutes what it ostensibly describes' (2014: 199, emphasis in original). Taking a critical stance, Willmott (2014) suggests that we should be sensitive to the "politics of representation' involved in conceptualizations by exploring the performative effects of adopting concepts.

Building on these insights, I will now show how negative dialectics enables us to further explore why the explanatory power of taxonomic categories is limited. Following Adorno (1983), identity thinking fails to acknowledge that every object contains additional dimensions or features that the concept overlooks or cannot encapsulate. Hence, concepts 'freeze' (Bernstein, 2004: 44) objects, 
negating their dynamic, fluctuating and ephemeral character. It follows that concepts can never fully encompass objects, because there is always a 'nonidentity' (Adorno, 1983: 111) between the two. Experience, on Adorno's account, therefore rests on a contradiction between concepts and objects. In contrast, identity thinking overlooks this contradictory relationship, since it conflates objects with their respective concepts. To explore this contradiction, Adorno proposes a procedure for detecting the nonidentity between concepts and objects. We can clearly grasp the 'nonidentical element in an identifying judgement', according to Adorno, when we realize that 'every single object subsumed under a class has definitions not contained in the definition of the class' (1983: 150). The task of negative dialectics, then, consists of showing how objects cannot be reduced to their conceptual representation. In this way, negative dialectics protects 'the thing's own identity against its identification' (Adorno, 1983: 161).

If we return to the example that we used in the previous section, then we can see how we protect the object against its concept. When we assert that a non-profit corporation is an organization, we evoke the term 'is' to signify that the non-profit corporation belongs to the concept of organization insofar as it allows its members to coordinate their actions to achieve specific goals. But this identifying judgement is an abstraction, since it evades rather than outlines the uniqueness of the non-profit corporation (for general argument, see Adorno, 1983: 150; Jarvis, 1998: 166). It says only that the non-profit corporation is part of class of phenomena called 'organization' but says nothing about what a non-profit corporation is or does. The assertion accentuates that the non-profit corporation belongs to the category of organization without accounting for its specific features, such as the use of surplus revenues for a certain mission instead of distributing profit to shareholders. Nor does the assertion that the non-profit corporation is an organization say anything about how the non-profit corporation emerges, evolves and develops over time. Quite the opposite, the assertion gives the impression that the non-profit corporation remains a stable unity with a consistent structure. For this reason, the concept here performs a 'de-temporalization of what it refers to' (Adorno, 2002b: 70). In sum, as opposed to telling us what a non-profit corporation actually 'is', the assertion ultimately amounts to stating that the object can be subsumed under a concept. But such a subsumption fails to adequately account for the complex nature or specificity of the object at hand (Neimark and Tinker, 1987: 663). 
One might develop the argument further here and show how the 'non-profit corporation' is itself a generalized concept that fails to encompass the objects subsumed under this taxonomic category. Notwithstanding, the basic lesson here is that concepts suffer from a 'deficiency' (Adorno, 2002b: 70) that prevents them from incorporating the richness of the objects they presume to describe. As Sørensen notes, 'all abstractions are simple; everything that is concrete is complex' (2004: 12). Following Adorno, we should not use such occasions to enlarge the concept of organization in order to provide a comprehensive definition that can cover all aspects of objects. Instead, we should recognize that the organizational phenomena we encounter always contain multiple layers of meaning and a myriad of dimensions that cannot be contained within a single definition. Since organizational phenomena are elusive, temporal, fluctuating and ephemeral, they cannot be encapsulated within a unifying concept (Clegg et al., 2005). The myriad of diverse objects associated with organization cannot simply be 'synthesized under a single concept' (Adorno, 2002b: 32). Instead of reducing organizations to an object that can be represented conceptually, we should therefore remain attentive to the dimensions of the objects that escape the concept, the features that 'slip away' from our effort to conceptualize them. In doing so, we can resist the tendency towards rigidification of organization by the concept.

\section{Why we are bad at thinking movement}

So far, we have looked at how conceptualizations of organization involve identity thinking. As well, we have seen how a negative dialectics approach allows us to disclose the friction between the concept of organization and those objects it tries to subsume. Still, although concepts solidify experience by imposing taxonomic categories upon what is actually indeterminate, fluctuating and complex, this does not entail that we can do without concepts altogether (Neimark and Tinker, 1987). Such a view, says Adorno (2002a), would connote a naïve belief that we can gain unmediated access to the processual nature of reality by arriving at a privileged epistemological position. Adorno states that we 'can see through the identity principle, but we cannot think without identifying' (1983: 149). All experience is conceptually mediated, since every observation is guided by concepts, categories and words that function as frameworks for interpretation (see also Helin et al., 2015: 10). Hence, there is no 'ostensible "factual" data' 
available to us without conceptual representation' (Willmott, 2014: 191). When we study the objects given in experience, then we need concepts in order to symbolize, denote and represent them. At the same time, as we have seen, the concepts we evoke are incapable of capturing the richness of objects.

Consequently, negative dialectics highlights how we need concepts to describe objects while these very concepts are notoriously unable to exhaust objects. In line with Bateson, Adorno stresses that we should accept 'the difference between the categories we produce and the world of phenomena they are designed to capture' (Zundel et al., 2013: 103). But Adorno maintains that it is in the moment when we recognize the discrepancy between concepts and objects, that we gain the opportunity to experience the elusive state of things and the processual nature of the world. For Adorno, 'the only way to do justice to the priority of the object is by pushing subjective mediated identifications to the point where they collapse' (Jarvis, 1998: 184). Or to put it in a slightly different manner, it is when concepts and objects diverge that objects reveal their processual nature that refuses to be inscribed within taxonomic categories. Hence, Adorno does not argue that we should abandon concepts or design concepts that are able to represent objects. Instead, we should learn to take advantage of the discrepancy between concept and object, since it is in this discrepancy that understanding processual nature of the world takes place.

Process-based approaches have been introduced into organization studies in an effort to think beyond static categories that depict the organization as a fixed entity (Chia, 1999; Clegg et al., 2005; Helin et al., 2014; Hjorth et al., 2015; Tsoukas and Chia, 2002; Van de Ven and Poole, 2005). In accordance with this view, Benson claims that dialectics must indeed be considered 'essentially a processual perspective' (1977: 2), since it insists on the dynamic, changing and fluctuating nature of objects. However, negative dialectics can contribute to processual research in organization studies by showing us precisely why the fluid, restless and ephemeral nature of the world remains so immensely difficult to capture and why we are, in the words of Cooper, 'not good at thinking movement' (1998: 128; see also Chia, 1999; Nayak, 2008; O’Doherty, 2008). For Adorno, there is no easy way to think the changing nature of objects, because the concepts that we have at our disposal do not allow us to view, much less reflect upon, the processual nature of the world. Yet these very concepts are paradoxically necessary for thinking. We must 
therefore continuously struggle against the attempt to petrify objects by sing concepts and instead strive to open critical spaces in which playful, dynamic thinking is allowed to emerge (O’Doherty, 2008).

Given the strong emphasis on destabilizing totalizing concepts, it is no wonder that Parker (2003) calls negative dialectics a 'quasi-deconstructive' approach. Clearly, Adorno shares with Derrida the suspicion that the language we use cannot accurately mirror reality, what has been called 'the crisis of representation' (Cunliffe, 2003) in organization studies. On this basis, negative dialectics draws attention to 'what cannot be subsumed under identity', according to Jameson (2007: 23). Instead of constructing categories that represent social reality, negative dialectics requires that each concept we use be 'analysed symptomatically for what it excludes or cannot say' (Jameson, 2007: 37). Jameson elaborates that:

\footnotetext{
What Adorno reproaches the sociologists with generally is that they do not get on with that work [i.e. analysing concepts for what they exclude or cannot say], but rather assumes that the larger or more abstract 'concepts' - such as society, freedom, bureaucracy, domination - are the end-point of thinking and the ultimate framework of interpretation. On the contrary, these concepts demand dialectical analysis the most urgently, and it is by way of their formal pseudo-universality and 'scientific' abstraction that the ultimate shackle which the social imposes on our thinking about the social becomes revealed although not removed (Jameson, 2007: 37).
}

Although Jameson mentions 'bureaucracy', 'society', 'freedom' and 'domination', we might add to his list other concepts that remain equally central to organization studies, including the concept of 'organization' itself, which we have touched upon. In this vein, negative dialectics should engage with concepts such as 'innovation', 'co-creation' or 'creativity' which have gained tremendous momentum in recent years. In organization studies, we use a variety of broad 'umbrella constructs' (Hirsch and Levin, 1999) to render organizational realities visible. Negative dialectics encourages us to explore what these overarching concepts exclude, ignore or overlook. A concept should not provide the point of departure for an engagement with organization. It is the concepts themselves that should become the target of critique (Curtis, 2014). In this way, the concept itself becomes the focal point of the processual investigation. However, the point here is not to stop studying organizational practice. On the contrary, we should be aware of how 
concepts are utilized in the study of organizational practices, but also how these concepts are never fully able to encompass the objects we encounter.

\section{Are organizations invisible?}

Up till now, we have looked at how concepts fail to account for the complex, indeterminate and temporal nature of objects. Let us now consider to what extent the problem of conceptualizing organization derives from the lack of observable practices or activities accessible to researchers. This will also help us to understand how negative dialectics can be used to explore the processual nature of organization. Asking the epistemological question 'How do we know that something is an organization?', Parker (2016: 100) maintains that the empirical evidence cited in order to determine the presence of an organization is usually inadequate. For example, we might enter a building populated by individuals who we consider as being part of an organization, but the presence of such a building and the presence of a group of people do not constitute sufficient conditions for us to conclude that we are dealing with an organization. Thus, Parker elaborates that even "when we visit a building that "contains" an organization, we don't see "it" but instead an intense display of the materials and events that signify it' (2016: 100).

Here I will show how negative dialectics allows us to address this epistemological challenge. In order to illustrate this, I shall use an example from my own experience of studying organization. I recently visited the newly renovated headquarters of the Confederation of Danish Industry, the major Danish business association (known as DI) with the purpose of understanding the 'organization'. At first sight, the office located in a newly renovated 12-story building on Copenhagen's City Hall Square displayed all the characteristics that are associated with a typical 'neo-bureaucratic organization' - that is, a hybrid configuration of centralized management and decentralized project teams (Reed, 2011). While the workspaces were arranged as open landscapes, ostensibly in order to stimulate collaboration, the DI building itself was hierarchically ordered, with top management placed on the upper floor. In light of these observations, I was inclined to pass an identifying judgement linking the concept of organization with the various objects that I encountered and observations made at DI headquarters. Nevertheless, observing employees working in an office, as Parker (2016) rightly notes, is not the same as observing an 
organization. All the same, it remained evident that the building populated by the people who I was visiting presented itself in these terms. It quickly occurred to me that I was situated in a social context that epitomized itself through an 'organizational diagram' wherein the CEO of DI was placed at the top of the managerial pyramid (see Figure 1). In addition, the people with whom I spoke constantly referred to DI as the organization. We can see here that the concept of organization is not simply a theoretical abstraction that remains detached from a concrete practice. As Adorno teaches us, concepts are embedded 'in society itself' (2002a: 32) insofar as practice is wedded to taxonomic categories that are used to arrange, systematize and subsume objects.

Viewed from the perspective of negative dialectics, the headquarters that I was visiting contained an 'organization'. It did not contain an organization simply because I used a theoretical concept to label an empirical object. Rather, DI was an organization because the object encountered here assumed the form of an organization by virtue of its mode of conceptual representation. In other words, the organizational diagram-depicting the organizations as different divisions governed by different layers of management - portrayed the social context that I was part of as an organization (see Figure 1). Such an organizational diagram is obviously a simplification of what is otherwise a more complicated chain of social relations and activities. However, it is precisely the role of negative dialectics here to unveil the politics involved in these representations by exposing the way in which organizational phenomena are always something more than the concepts used to label them. To carry out this unveiling process, we need to pay attention to the myriad of multi-layered objects that the concept of organization comprises.

\section{Insert Figure 1 about here}

One of the seemingly ordinary phenomena that caught my attention during my visit to DI was the display of CEO portraits in the lobby (see Figure 1). On one of the walls, there was a collection of oil paintings portraying the previous DI executive directors. Enclosed within golden frames, all the paintings portrayed middle-aged white males wearing dark suits, all with a distinguished posture that symbolized power and authority. Guthey and Jackson (2005) argue that CEO portraits can be important in order to convey the organization into a visual representation. 'Since 
no one has ever "seen” an organization or corporation', Guthey and Jackson (2005: 1057) explain, such images serve to 'visualize' it. In light of this, one might say that these CEO portraits deployed in the lobby had the function of giving a face to the organization by providing a visible expression to what is otherwise an abstract concept. These CEO portraits coincided with the organizational diagram in that they both attempted to structure the organization into an ordered unity wherein the CEO featured at the top of the hierarchy.

Depicting the organization through CEO portraits, however, is not without contradictions. On one level, the contradiction in the objects here seems apparent, since these CEO portraits cannot achieve a visual representation of the organization without ignoring the fact that they are merely pictorial expressions. As one could say with Žižek, these CEO portraits might express the 'sublime' surface of the organization, but once we get close to them, the portraits dissolve into 'ordinary' objects (2008: 192). Strictly speaking, these objects are merely pictures hanging on the wall; not the 'organization' as such. If we equate the CEO portrait with the organization, we confuse concrete things (i.e. the portraits) with an abstract concept (i.e. the organization). But beyond this effort at identification, what was remarkable about these CEO portraits was the manner in which they were arranged on the wall. Typically, such portraits are placed near the ceiling so that the spectator has to gaze at them from a distance. Such distance effectually preserves the sublime surface of objects and ensure that their aura remain intact. But in this case, some of the CEO portraits were placed below eye level. In effect, the visitor walking through the corridor had to stare down on these CEO portraits. Instead of being elevated to the top of the organizational pyramid, CEO portraits were located downward.

As a result, the CEO portraits diverged from the organizational hierarchy they were supposed to represent. Thus, these CEO portraits invited a deconstructive engagement wherein the object 'loses its aura and is returned to use' (Agamben, 2007: 77; see also Śliwa, Spoelstra, Sørensen and Land, 2012). They returned to use, precisely because the spectator was allowed to engage and 'dwell' with them (Chia and Holt, 2006). Confronted with these portraits, I asked myself the naïve question: Why is the CEO always placed on the top of the organizational diagram? For some, the answer might be obvious: the CEO embodies the vision, signifies the shared purpose of the organization and so forth. And yet, the display of these CEO portraits left traces of radical 
contingency, as they remind us of how things can always be otherwise. Here we enter into the politics of representation by exposing the issues at stake within conceptualizations. We can see how the world is always categorized in a certain way. Yet we can also see that these categorizations foreshadow the temporality and indeterminacy of the world. On the one hand, the portraits freeze the CEO function, signifying as they do a consistent succession of leaders who are elevated to the top of the organizational hierarchy. On the other hand, however, the display of these past leaders shows how the CEO function is only momentary, since nobody serves this function forever. If we look closely, we can see how the CEO portraits reveal the fact that the organizational diagram could be categorized in a different way, since the objects here contain unexplored potentials that are not accounted for by the concept.

Gazing at these CEO portraits, we can therefore appreciate how the object - the CEO portraits incongruously displayed below eye level—diverges from its respective concept - the organizational diagram elevating the CEO to of the hierarchy. In turn, we can use this occasion to push identity thinking to the edge by revealing how objects are ridden with contradictions that result from the attempt to subsume them under concepts. We can now engage with objects unencumbered by their defining concept and explore the indeterminate potentiality embedded in them. We can entertain the idea of what the object might become instead of simply assuming that it has a fixed location, form and content. While identity thinking would reify these CEO portraits into static entities, negative dialectics can allow us to engage with them by confronting objects with their respective concepts. We can begin to appreciate how objects cannot be inscribed within taxonomic categories and henceforth engage with concepts in order to think beyond them. In Adorno's words, we 'must strive, by way of the concept, to transcend the concept' (1983: 15). We cannot escape concepts that impose order onto the otherwise undifferentiated flux of experience. But we can explore the processual dimensions of objects by revealing what such concepts overlook. In this way, we can transcend the concept of organization by confronting the myriads of multifaceted, indeterminate and fluctuating objects it contains.

Obviously, it is easy here to dismiss these CEO portraits as minor artefacts of organization without much importance. But we may be too quick to dismiss such objects, because our propensity to identity thinking pushes to retreat into abstractions. Without doubt, we are only 
here scratching the surface of what are arguably much more delicate questions of power, authority and hierarchy taking place within this organization. Still, the confrontation of contradictory objects constitutes a useful point of departure for addressing such issues. When we arrange the organizations diagrams and define them as social units that contain shared purposes, we ignore the conflict of interests, power struggles and intrigues that reside within these units. In addition, we overlook the processes of change and fluidity that animate organizations. And we overlook the contingent constructions that permeate social relations. This does not mean, however, that a recourse to verbs will be sufficient to capture such processes. Instead, we should look for the gap that lies between the manner in which we categorize objects and the objects themselves. Here we can be receptive to how objects can surprise us and appreciate their unexplored potentials. We can be attentive to the unique and particular aspects of organizational phenomena by cultivating the capacity to hold ourselves 'open to whatever experience presents itself to the mind' (Adorno, 2008: 75). On this basis, we can use the contradiction between the object and its associated concept in order to explore the multiple layers of meaning contained within organizational phenomena. In doing so, we carry out a negative dialectics of organization.

\section{Concluding discussion}

At the outset, this paper drew attention to recent critics' lament about the 'strikingly missing the 'O' in organization theory' (King et al., 2010: 291) following the emergence of process-based approaches. Should the organization be the centre of attention in organization studies? Or should we replace the noun organization with the verb organizing? On the one hand, there are those who maintain that the concept of organization is a static category that fails to capture dynamic processes of organizing (Weick, 1995). On the other hand, there are those who believe that we should recover the organization as a unit of analysis (King et al., 2010). Bakken and Hernes (2006) attempt to reconcile these two positions by showing how verbs and nouns are mutually constitutive. Instead of following this route, I have suggested an alternative approach to the question of conceptualizing organization. As I have demonstrated, most attempts to conceptualize organization are based upon identity thinking. Against identity thinking, I have argued that the non-identity between concepts and objects implies that the operation of conceptually represented organizational realities always leaves out something important. In turn, I have suggested that we 
should continue to engage with the concept of organization, but to be attentive to precisely those dimensions of the object that escape the concept.

Rather than overcoming the gap between concepts and objects, we should embrace the contradictions encountered between concepts and organizational phenomena. What we encounter in organizations are not circumscribed social entities that contain features, elements and traits that can be easily recognized and theoretically portrayed through concepts. Instead, we encounter objects that are ridden with contradictions, objects that evade our conventional categories and phenomena that resist theoretical articulation. Confronted with the contradiction between the concept and its respective object, writing about organization can no longer take its point of departure in static categories based on general categories of what an organization 'is' (Clegg et al., 2005). Instead, writing about organization must enter into an experimental mode wherein contradictions are allowed to prevail (Helin, 2015; Rhodes, 2009; O’Doherty, 2007). There is no value in appealing to some kind of overarching synthesis intended to highlight the interrelations between mutually exclusive elements. This kind of approach will provide only a false appearance of reconciliation between the concept and the object. On the contrary, we must try to think beyond taxonomic categories by paying attention to that which such concepts exclude, ignore or suppress (Jameson, 2007). A negative dialectics of organization should hold that it is only on the condition of contradiction between the concept and the object that we can experience the temporal, complex and shifting dimensions of organizational phenomena.

Helin et al. note that to 'investigate organizational life' from a processual perspective 'is to use representational concepts whilst being attentive to how they can, in turn, use us, confining our vision with prescriptions of neatness that find us smoothing over the frayed and recalcitrant aspects of experience' (2015: 10). Herein lies the contradiction that negative dialectics must wrestle with without a simple solution or final endpoint. We can only think the changing nature of objects through concepts. Yet, concepts are themselves static taxonomic categories. Here negative dialectics can contribute to developing a processual approach to organization by revealing how concepts fail to capture the indeterminate possibilities of objects. Such an exercise is not simply a theoretical endeavour that remains detached from practice. Instead, we should become sensitive to how the concept of organization appears in practice and is evoked in order to 
describe and categorize objects. Here we can engage with how organizations use diagrams, charts and models in order to represent themselves.

From a sensemaking perspective, concepts can be manipulated by actors in practice in order to 'make retrospective sense of what occurs' (Weick, 1993: 635). Thus, concepts do not represent the organization. Rather, they are a tool for organizing the organization by subsuming the myriads of events, things and phenomena under comfortable taxonomic categories. In turn, organizational members may deploy such 'cognitive categories' (Tsoukas and Chia, 2002: 573) in order to solve problems and render their surroundings comprehensible. However, as Munro and Huber (2012) emphasize, sensemaking presupposes that social events can be made intelligible and that we can arrive at plausible solutions to problems. What we encounter in daily interactions, however, is often meaninglessness rather than meaning, or the fact that no plausible solution is available. Munro and Huber (2012: 534) pick up on Adorno's reading of Kafka to elaborate on this point. As Munro and Huber remark, Adorno draws attention to how Kafka was able to reveal 'the deeply flawed and, in his words, "broken" qualities of language' by showing the misunderstanding that prevails in communication.

What Adorno finds interesting in Kafka's novels is precisely how they reveal the contradictions embedded in social relations. Thus, as Adorno states, Kafka's works demonstrate how 'absurdity is as self-evident as it has actually become in society' (2006: 231). In a similar fashion, a negative dialectical engagement with organization should be sensitive to the way in which organization is ridden with contradictions, absurdities and lack of meaning. Conceptualizations of organization should not strive to extract linear, homogeneous and consistent taxonomic categories out of the myriad of experiences encountered in organizations that, in turn, can be used to classify objects. It is therefore not a matter of escaping contradictions, since that would only remove us away from the objects themselves and push our thinking into an abstract mode of conceptualization. On the contrary, conceptualizations of organization should allow the contradictions embedded in the objects themselves to come to light. To do so, we need to be aware of the contradictions that occur between the concepts we compose and the objects we encounter. 
In this way, a negative dialectics of organization should move us into a space in which 'suspended' and 'self-cancelling' thinking and writing (O'Doherty, 2008: 541) will be tolerated. We need to ceaselessly experiment with the concept of organization in order to think beyond it. Negative dialectics can contribute to developing a processual approach to organization by continuously contesting the attempt to restrict the dynamic, changing and fluctuating nature of objects within concepts and thereby strive to open critical spaces in which playful thinking is allowed to emerge. To allow for contradictions to unfold themselves in writing is to allow for thinking to explore what lies beyond the scope of identity thinking. It is here that we can begin to appreciate that organization not only signifies a privileged set of objects that are assumed to remain homogeneous and coherent. Instead, we begin to acknowledge how organization can indeed manifest itself in diverse ways, but also why our thoughts are bent towards abstract categories that hide the complexity of the world (Cooper, 2005). In other words, with negative dialectics, we begin to understand organization as a phenomenon that cannot be reduced to a conceptual representation, but rather a contradictory object that can take numerous shapes and forms. With the antagonism between the concept and object, negative dialectics can help to express the inexpressible and represent the unrepresentable.

\section{References}

Adorno, T. W. (1983) Negative dialectics. New York: Continuum.

Adorno, T. W. (2002a) Introduction to Sociology. Stanford: Stanford University Press.

Adorno, T. W. (2002b) Metaphysics: concept and problems. Stanford: Stanford University Press.

Adorno, T. W. (2006) Aesthetic theory. (G. Adorno and R. Tiedemann, Eds.) Minneapolis, Minnesota: University of Minnesota Press.

Adorno, T. W. (2008) Lectures on negative Dialectics: Fragments of a lecture course 1965/1966. Cambridge: Polity.

Agamben, G. (2007) Profanations. New York: Zone Books.

Anderson, M. H. (2006) 'How can we know what we think until we see what we said? A citation and citation context analysis of Karl Weick's the social psychology of organizing' Organization Studies, 27(11): 1675-1692. 
Bakken, T., and Hernes, T. (2006) 'Organizing is both a verb and a noun: Weick meets Whitehead', Organization Studies, 27(11): 1599-1616.

Barnard, C. I. (1968) The functions of the executive. Cambridge, Massachusetts: Harvard University Press.

Benson, J. K. (1977) 'Organizations: A dialectical view', Administrative Science Quarterly, 22(1): 1-21.

Bernstein, J. M. (2004) Negative dialectic as fate: Adorno and Hegel. In T. Huhn (Ed.), The Cambridge Companion to Adorno. Cambridge: Cambridge University Press.

Chia, R. and Holt, R. (2006) 'Strategy as practical coping: A Heideggerian perspective', Organization Studies, 27(5): 635-655

Chia, R. (1995) 'From modern to postmodern organizational analysis', Organization Studies, 16(4): 579-604.

Chia, R. (1999) 'A "rhizomic” model of organizational change and transformation: Perspective from a metaphysics of change', British Journal of Management, 10(3): 209-227.

Clegg, S. R., Kornberger, M., and Rhodes, C. (2005) 'Learning/Becoming/Organizing', Organization, 12(2): 147-167.

Cooper, R. (1986) 'Organization/Disorganization', Social Science Information, 25(2): 299-335.

Cooper, R. (1998) Assemblage notes. In R. Chia (Ed.), Organized worlds (pp. 131-180) London: Routledge.

Cooper, R. (2005) 'Peripheral vision: Relationality’, Organization Studies, 26(11): 1689-1710.

Cunliffe, A. L. (2003) 'Reflexive inquiry in organizational research: Questions and possibilities', Human Relations, 56(8): 983-1003.

Cunliffe, A. L. (2008) Organization Theory. Los Angeles and London: SAGE.

Curtis, R. (2014) 'Foucault beyond Fairclough: From transcendental to immanent critique in organization studies', Organization Studies. 35(12): 1753-1772.

Guthey, E., and Jackson, B. (2005) 'CEO portraits and the authenticity paradox', Journal of Management Studies, 42(5): 1057-1082.

Hatch, M. J., and Cunliffe, A. L. (2013) Organization theory: Modern, symbolic and postmodern perspectives. Oxford: Oxford University Press.

Helin, J. (2015) Writing process after reading Bakhtin from theorized plots to unfinalizable “living” events. Journal of Management Inquiry, 24(2): 174-185. 
Helin, J., Hernes, T., Hjorth, D., and Holt, R. (Eds.) (2014) The Oxford handbook of process philosophy and organization studies. Oxford: Oxford University Press.

Hernes, T. (2007) Understanding organization as process: Theory for a tangled world. London and New York: Routledge.

Hernes, T. (2014) A process theory of organization. Oxford: Oxford University Press.

Hernes, T., and Weik, E. (2007) 'Organization as process: Drawing a line between endogenous and exogenous views', Scandinavian Journal of Management, 23(3): 251-264.

Hirsch: M., and Levin, D. Z. (1999) 'Umbrella advocates versus validity police: A life-cycle model', Organization Science, 10(2): 199-212.

Hjorth, D., Holt, R., and Steyaert, C. (2015) 'Entrepreneurship and process studies', International Small Business Journal, 33(6): 599-611.

Jameson, F. (2007) Late marxism: Adorno, or, the persistence of the dialectic. London: Verso.

Jarvis, S. (1998) Adorno: A Critical Introduction. New York: Routledge.

King, B. G., Felin, T., and Whetten, D. A. (2010) 'Perspective - Finding the organization in organizational theory: A meta-theory of the organization as a social actor', Organization Science, 21(1): 290-305.

Linstead, S. and Thanem, T. (2007) Multiplicity, virtuality and organization: The contribution of Gilles Deleuze. Organization Studies, 28(10): 1483-1501

Lopdrup-Hjorth, T. (2015) 'Object and objective lost?', Journal of Cultural Economy, 8(4): 439461.

Mintzberg, H. (1983) Structure in fives: Designing effective organizations. Prentice Hall.

Mumby, D. K. (2005) 'Theorizing resistance in organization studies a dialectical approach', Management Communication Quarterly, 19(1): 19-44.

Munro, I., and Huber, C. (2012) 'Kafka's mythology: Organization, bureaucracy and the limits of sensemaking', Human Relations, 65(4): 523-543.

Nayak, A. (2008) 'On the way to theory: A processual approach', Organization Studies, 29(2): $173-190$.

Neimark, M., and Tinker, T. (1987) 'Identity and non-identity thinking: Dialectical critique of the transaction cost theory of the modern corporation', Journal of Management, 13(4): 661673. 
Nielsen, R. P. (1996) 'Varieties of dialectic change processes', Journal of Management Inquiry, 5(3): 276-292.

O’Doherty, D. P. (2007) 'The question of theoretical excess: Folly and fall in theorizing Organization', Organization, 14(6): 837-867.

O’Doherty, D. P. (2008) 'The blur sensation: Shadows of the future', Organization, 15(4): 535561.

Parker, M. (2003) Business, ethics and business ethics: Critical theory and negative dialectics, in Alvesson, M and Willmott, H. (eds.), Studying management critically, London: Sage (pp. 197-219)

Parker, M. (2007) ‘Organizing: Skyscrapers and multitudes', Critical Perspectives on International Business, 3(3): 220-225.

Parker, M. (2016) 'Secret societies: Intimations of organization', Organization Studies, 37(1): 99-113.

Reed, M. (2011) The post-bureaucratic Organization and the control revolution. In Clegg, S. R., Harris, M. and Höpfl, H. (eds.) Managing modernity: Beyond bureaucracy? Oxford: Oxford University Press.

Rhodes, C. (2009) 'After reflexivity: Ethics, freedom and the writing of organization studies', Organization Studies, 30(6): 653-672.

Robbins, S. P. (1990) Organization theory: Structures, designs and applications, New Jersey: Prentice Hall.

Scott, W. R. (1998) Organizations: Rational, natural, and open systems. New Jersey: Prentice Hall.

Shotter, J. (2006) 'Understanding process from within: An argument for 'withness'-thinking', Organization Studies. 27: 585-604

Śliwa, M., Spoelstra, S., Sørensen, B. M., and Land, C. (2013) 'Profaning the sacred in leadership studies: A reading of Murakami's a wild sheep chase', Organization. 20(6): $860-880$

Sørensen, B. M. (2004) Making events work: Or, how to multiply your crisis. Copenhagen: Copenhagen Business School.

Spoelstra, S. (2007) What is organization?, Lund: Lund University 
Stone, A. (2014) 'Adorno, Hegel, and Dialectic', British Journal for the History of Philosophy, 22: $1118-1141$.

Suddaby, R. (2010) 'Editor's comment: Construct clarity in theories of management and organization', Academy of Management Review, 35: 346-357.

Tsoukas, H. (2005) Complex knowledge: Studies in organizational epistemology. Oxford: Oxford University Press.

Tsoukas, H., and Chia, R. (2002) 'On organizational becoming: Rethinking organizational change', Organization Science, 13: 567-582.

Tsoukas, H., and Knudsen, C. (2005) The Oxford handbook of organization theory. Oxford: Oxford University Press.

Van de Ven, A. H., and Poole, M. S. (2005) 'Alternative approaches for studying organizational change', Organization Studies, 26(9): 1377-1404.

Weick, K. E. (1979) The social psychology of organizing. New York: McGraw-Hill.

Weick, K. E. (1993) 'The collapse of sensemaking in organizations: The mann Gulch Disaster', Administrative Science Quarterly, 38(4): 628-652.

Weick, K. E. (1995) Sensemaking in organizations. London: Sage.

Weick, K. E., Sutcliffe, K. M., and Obstfeld, D. (2005) 'Organizing and the process of sensemaking', Organization Science, 16(4): 409-421.

Weik, E. (2011) 'In deep waters: Process theory between Scylla and Charybdis', Organization, 18(5): 655-672.

Willmott, H. (2014) Conceptually grounded analysis: The elusive facticity and ethical upshot of “Organization”, in Emma Jeanes and Tony Huzzard (eds.), Critical Management Research: Reflections from the Field, London: Sage

Zundel, M., Holt, R., and Cornelissen, J. (2013) 'Institutional work in the wire an ethological investigation of flexibility in organizational adaptation', Journal of Management Inquiry, 22: $102-120$. 